\title{
Long-Term Efficacy of Vismodegib After its Withdrawal and Patients' Health-Related Quality of Life Using the Dermatology Life Quality Index (DLQI)
}

\author{
Alessia Villani · Matteo Megna · Gabriella Fabbrocini • \\ Milena Cappello · Maria Antonietta Luciano - Claudia Costa • \\ Massimiliano Scalvenzi
}

Received: July 26, 2019 / Published online: September 10, 2019

(C) The Author(s) 2019

\section{ABSTRACT}

Introduction: Although non-melanoma skin cancers (NMSCs) are associated with a very low mortality risk, they have been reported to have a major impact on patients' health-related quality of life (HRQoL). Vismodegib is a therapy for patients who are affected by locally advanced basal cell carcinoma (BCC) or metastatic BCC who are ineligible for surgery and/or radiotherapy. The aim of the present clinical study was to assess the long-term efficacy of vismodegib after its withdrawal by evaluating the recurrence rate of advanced BCC, assessing also patients' HRQoL after 3 and 6 months from drug withdrawal.

Methods: A retrospective study was performed to analyze patients with advanced and/or multiple BCCs that had been treated with vismodegib (150 mg daily) at the Non-Melanoma Skin Cancer Unit of the University of Naples Federico II (Italy) and had obtained a complete regression in 6 months. At the end of the

Enhanced Digital Features To view enhanced digital features for this article go to https://doi.org/10.6084/ m9.figshare.9746486.

A. Villani $(\bowtie) \cdot$ M. Megna · G. Fabbrocini ·

M. Cappello · M. A. Luciano · C. Costa .

M. Scalvenzi

Dermatology Unit, Department of Clinical Medicine

and Surgery, University of Naples Federico II,

Naples, Italy

e-mail: ali.vil@hotmail.it 6-month treatment cycle, patients that reported total remission of the skin tumor were visited monthly in order to assess their therapeutic response. Moreover, to assess the specific impact of vismodegib on HRQoL, DLQI was administered before vismodegib treatment (baseline), at the end of the therapy cycle (6 months), as well as after 3 and 6 months from vismodegib discontinuation.

Results: Thirty-five patients (27 male, 8 female), with a complete regression of their advanced BCC after vismodegib treatment, were included in the study. The duration of treatment for all patients was 6 months as set by study inclusion criteria. A BCC recurrence rate of $31 \%(11 / 35)$ was reported after a 6-month follow-up. The average reported Dermatology Life Quality Index (DLQI) score increased from a value of 0 at the end of the 6 -month vismodegib treatment to a mean value of 2.4 after 3 months from drug withdrawal and 3.6 after 6 months from treatment discontinuation.

Conclusion: The results of this exploratory analysis of vismodegib withdrawal are consistent with a substantial link between treatment response and patients' HRQoL. Furthermore, 11 out of $35(31 \%)$ patients that reported a complete remission of the disease after 6 months of vismodegib treatment reported BCC recurrence. These data highlight the importance of continuous follow-up and perhaps different regimens of treatment, such as an alternate dose regimen to maintain disease control and reduce 
the adverse events as previously described in the literature.

Keywords: Basal cell carcinoma; DLQI; Drug withdrawal; Quality of life; Skin cancer; Vismodegib

\section{INTRODUCTION}

Non-melanoma skin cancer (NMSC) is one of the most common tumors, presenting an increasing incidence with an estimated five million new cases each year [1]. Although NMSCs are associated with a very low mortality risk, they have been reported to have a major impact on patients' health-related quality of life (HRQoL) [2]. The high burden on quality of life is due to the symptomatology of the tumor, treatments (both pharmacological and surgical), as well as the therapy-related adverse events [3]. Basal cell carcinoma (BCC) is the most common NMSC. Although surgery is the first-line therapy for BCC, some cases can progress to an advanced or-very rarely-a metastatic state, frequently requiring nonsurgical approaches such as cryotherapy, adjuvant radiotherapy, and targeted therapy [4]. Vismodegib is a Hedgehog pathway inhibitor therapy for patients who are affected by locally advanced BCC or metastatic BCC and who are ineligible for surgery and/or radiotherapy [5]. Approximately $80 \%$ of BCCs occur in the head and neck region and may cause disfiguring skin changes that impact on the patient's body image and HRQoL [6]. Although vismodegib has been demonstrated to be a safe and effective drug, it is particularly important to understand its long-term efficacy. Indeed, there are no studies which report the rate of efficacy of vismodegib after treatment discontinuation and the rate of BCC recurrences in patients that underwent this therapy. Moreover, data on HRQoL after vismodegib discontinuation are lacking. Therefore, the aim of the present clinical study was to assess the long-term efficacy of vismodegib after its withdrawal by evaluating the recurrence rate of advanced BCC, assessing also patients' HRQoL after 3 and 6 months from drug withdrawal using the Dermatology Life Quality Index (DLQI) [7].

\section{METHODS}

A retrospective study was performed to analyze patients with advanced and/or multiple BCCs that had been treated with vismodegib $(150 \mathrm{mg}$ daily) at the Non-Melanoma Skin Cancer Unit of the University of Naples Federico II (Italy) and had obtained a complete regression in 6 months from November 2016 to November 2018. Patients were enrolled consulting the computer-based database of the Non-Melanoma Skin Cancer Unit of the University of Naples Federico II (Italy). For each patient, demographic and clinical variables (localization, size, and variant of the BCCs) were registered. At the end of the 6-month treatment cycle, patients that reported total remission of the skin tumor were visited monthly in order to assess their therapeutic response by evaluating the BCC recurrence rate (RR). BCC remission was defined as the absence of tumor signs on clinical, dermoscopic, and confocal microscopy examinations. In doubtful cases, a 5-mm skin biopsy was performed to assess the absence of BCC cells. Moreover, to assess the specific impact of vismodegib on HRQoL, DLQI was administered before vismodegib treatment (baseline), at the end of the therapy cycle (6 months), as well as after 3 and 6 months from vismodegib discontinuation.

\section{Compliance with Ethics Guidelines}

All procedures performed in studies involving human participants were in accordance with the ethical standards of the University of Naples Federico II and with the 1964 Declaration of Helsinki and its later amendments or comparable ethical standards. Informed consent was obtained from all individual participants included in the study.

\section{RESULTS}

Thirty-five patients ( 27 male, 8 female), with a complete regression of their advanced BCC after vismodegib treatment, were included in the study. The median age was 74.5 years (ranging 
from 43 to 95 years). All patients had histologically confirmed advanced BCC. Thirty $(85.7 \%)$ of the BCCs were located on the head or neck, 3 $(8.6 \%)$ on the trunk, and $2(5.7 \%)$ were localized on the legs. At baseline, almost all patients (29; $82.8 \%$ ) had an ulcerative BCC type. The other reported clinical variants were multiple superficial and nodular BCCs (17.2\%). The duration of treatment for all patients was 6 months as set by study inclusion criteria. A BCC recurrence rate of $31 \%(11 / 35)$ was reported after a 6-month follow-up. The average reported DLQI score increased from a value of 0 at the end of the 6-month vismodegib treatment to a mean value of 2.4 after 3 months from drug withdrawal and 3.6 after 6 months from treatment discontinuation. DLQI score significantly increased in patients that presented a relapse of the disease. Scores in the "symptoms and feelings" subcategory significantly increased after treatment discontinuation with respect to scores in other subcategories that generally remained very low. DLQI values (median $\pm \mathrm{SD}$ ) after 6 months of treatment (t0) and after 3 (t1) and 6 months (t2) from vismodegib discontinuation are reported in Table 1.

\section{DISCUSSION}

BCC is the most common form of skin malignancy worldwide, accounting about $80 \%$ of all NMSC [2, 3]. Although BCCs are not lifethreatening conditions, they present a high impact on HRQoL, partly because they are frequently located on the head and neck region [8]. Vismodegib, an oral Sonic Hedgehog signaling pathway inhibitor, has recently been approved by the Food and Drug Association for the treatment of locally advanced, metastatic, and recurrent BCCs that are ineligible for surgery or radiotherapy $[8,9]$. Several studies have demonstrated the efficacy and safety of this small molecule which selectively connects to the Smoothened protein and blocks intracellular signaling, deactivating the Hedgehog pathway and thus inhibiting tumor growth [10]. However, data regarding eventual BCC rate recurrences and HRQoL impact after vismodegib discontinuation are lacking. Therefore, we performed a retrospective study to evaluate recurrence rates and quality of life impact on patients that had been treated with vismodegib and had reached a complete cancer regression after 6 months of treatment. In this study we enrolled only patients which achieved a complete remission of the skin disease after 6 months of vismodegib treatment $(n=35$; mean DLQI 0) in order to evaluate the longterm efficacy of vismodegib, the rate of recurrence, and thus the impact on patients quality of life.

We observed that $31 \%$ of patients reporting a complete BCC clearance with 6 months of vismodegib treatment showed skin tumor relapse after 6 months of therapy withdrawal. Consequently, an increased impairment of HRQoL was noticed in the same follow-up period; mean DLQI values significantly increased after 3 and 6 months of vismodegib discontinuation, being higher in patients experiencing a BCC relapse. A post hoc analysis demonstrated that DLQI total scores worsened relative to the objective signs of disease recurrence. Even a mild recurrence of the disease had a negative effect on DLQI scores, perhaps because patients recalled the previous deleterious effects of more severe disease activity on their HRQoL. In our previous study the mean overall DLQI score across 41 patients treated with vismodegib decreased from 5.7 at baseline to 0.4 after 6 months of treatment, indicating that vismodegib had a positive effect on the HRQoL of patients with BCC

Table 1 DLQI values [median \pm standard deviation (SD)] after 6 months of treatment (t0) and after $3(\mathrm{t} 1)$ and 6 months ( $t 2)$ from vismodegib discontinuation

\begin{tabular}{lll}
\hline $\begin{array}{l}\text { DLQI value [median } \pm \text { standard } \\
\text { deviation }(\mathrm{SD}) \text { ] after } \mathbf{6} \text { months of } \\
\text { treatment }(\mathbf{t})\end{array}$ & $\begin{array}{l}\text { DLQI value [median } \pm \text { standard } \\
\text { deviation }(\mathrm{SD}) \text { ] after } \mathbf{3} \text { months }(\mathbf{t} \mathbf{1}) \\
\text { from vismodegib discontinuation }\end{array}$ & $\begin{array}{l}\text { DLQI value [median } \pm \text { standard } \\
\text { deviation }(\mathrm{SD}) \text { ] after } \mathbf{6} \text { months }(\mathbf{t} 2) \\
\text { from vismodegib discontinuation }\end{array}$ \\
\hline 0 & $2.4 \pm 1.6$ & $3.6 \pm 2.8$ \\
\hline
\end{tabular}


(considering both patients with complete or partial BCC regression) [11].

The results of this exploratory analysis of vismodegib withdrawal, in all patients that had experienced a complete remission of the disease and so presented a DLQI value of 0 , are consistent with a substantial link between treatment response and patients' HRQoL. Furthermore, 11 out of $35(31 \%)$ patients that reported a complete remission of the disease after 6 months of vismodegib treatment reported BCC recurrence. These data highlight the importance of continuous follow-up and perhaps different regimens of treatment, such as an alternate dose regimen to maintain disease control and reduce the adverse events as previously described in the literature [12]. In recent years, different dose reduction strategies during routine treatment have been proposed as a means to reduce the severity of adverse events and achieve the optimum duration of vismodegib treatment. Transitioning from a continuous to an intermittent regimen could be a way to avoid dropouts [13]. NMSC also has an appreciable impact on patient QoL, especially for the locally advanced and the metastasizing forms of BCC, due to the symptomatology involved and the potential for physical disfigurement, which usually compromises the psychological state of the patient [6]. In a previous study, the mean overall DLQI score across 41 patients decreased from 5.7 at baseline to 0.4 after 6 months of treatment, indicating that vismodegib had a positive effect on patient HRQoL [11]. Indeed, the mean DLQI score in a normal population usually ranges from 0 to 0.5 [14]. Two other studies assessed HRQoL in patients with BCCs who were treated with surgery and observed a significant decrease in DLQI score 3 months after surgical intervention $[15,16]$. Moreover, a clinical study involving 25 patients with advanced BCCs who were treated with X-ray therapy showed a significant decrease in DLQI score to a normal level 3 months after treatment $(1.2 \pm 1.5$ at baseline to $0.4 \pm 0.9)$. However, literature data on HRQoL in patients with advanced BCCs who were treated with vismodegib are very limited. A phase 2 study on vismodegib safety, STEVIE (NCT01367665), which reported HRQoL outcomes in 730 patients with locally advanced BCCs and metastasizing BCCs, pointed out an improvement in HRQoL in all vismodegib-treated patients [17]. Furthermore, in a recent study Gualdi et al. assessed HRQoL in 10 patients treated with vismodegib, using the Self-Illness Separation (SIS) score. The authors reported that the average SIS score was inversely correlated to the average number of adverse events, which tended to increase during the intermittent therapeutic regimen [18].

To the best of our knowledge, this is the first study to demonstrate a significant change in patient HRQoL from baseline to 6 months after vismodegib initiation using DLQI. The average reported DLQI score increased from a value of 0 at the end of the 6-month vismodegib treatment to a mean value of 2.4 after 3 months from drug withdrawal and 3.6 after 6 months from treatment discontinuation. In particular, a significant decrease in the overall DLQI score was found, especially for the subcategory "symptoms and feelings", which significantly decreased from baseline to 6 months after treatment initiation, despite the occurrence of multiple adverse events. Interestingly, although patients with BCCs in visible areas such as the face or neck presented a higher DLQI score at the baseline visit than patients with BCCs on the trunk and legs, the scores for the two groups were very similar after 6 months of vismodegib therapy. A number of authors argue that the DLQI may not be specific enough to accurately evaluate the quality of life in patients with BCCs since this tool is tailored to patients with chronic skin conditions such as eczema or psoriasis. Hence, there is a strong need for a more disease-specific instrument that is validated for use in non-English-speaking countries.

\section{CONCLUSIONS}

Our study showed that about 30\% of patients with inoperable advanced BCCs treated with 6 months of vismodegib experienced disease relapse and HRQoL worsening with treatment discontinuation. Further studies are required to better manage Hedgehog pathway inhibitor-related adverse events and to validate a specific assessment of the HRQoL in patients who are 
undergoing this treatment. As a result of these limitations, this analysis must be considered exploratory and hypothesis-generating; a prospective study would be needed to confirm the findings.

\section{ACKNOWLEDGEMENTS}

Funding. No funding or sponsorship was received for this study or the publication of this article.

Authorship. All named authors meet the International Committee of Medical Journal Editors (ICMJE) criteria for authorship for this manuscript, take responsibility for the integrity of the work as a whole, and have given final approval to the version to be published.

Disclosures. Alessia Villani, Matteo Megna, Gabriella Fabbrocini, Milena Cappello, Maria Antonietta Luciano, Claudia Costa and Massimiliano Scalvenzi have nothing to disclose. Gabriella Fabbrocini is a member of the journal's Editorial Board.

Compliance with Ethics Guidelines. All procedures performed in studies involving human participants were in accordance with the ethical standards of the University of Naples Federico II and with the 1964 Declaration of Helsinki and its later amendments or comparable ethical standards. Informed consent was obtained from all individual participants included in the study.

Data Availability. The datasets generated during and/or analyzed during the current study are available from the corresponding author on reasonable request.

Open Access. This article is distributed under the terms of the Creative Commons Attribution-NonCommercial 4.0 International License (http://creativecommons.org/licenses/ by-nc/4.0/), which permits any noncommercial use, distribution, and reproduction in any medium, provided you give appropriate credit to the original author(s) and the source, provide a link to the Creative Commons license, and indicate if changes were made.

\section{REFERENCES}

1. Mohan SV, Chang ALS. Advanced basal cell carcinoma: epidemiology and therapeutic innovations. Curr Dermatol Rep. 2014;3(1):40-5.

2. Gaulin C, Sebaratnam DF, Fernández-Peñas P. Quality of life in non-melanoma skin cancer. Australas J Dermatol. 2015;56(1):70-6.

3. Abedini R, Nasimi M, Noormohammad Pour P, Moghtadaie A, Tohidinik HR. Quality of life in patients with non-melanoma skin cancer: implications for healthcare education services and supports. J Cancer Educ. 2018. https://doi.org/10.1007/ s13187-018-1368-y.

4. Scalvenzi M, Villani A, Mazzella C, Cappello M, Salvatores GF, Costa C. Vismodegib treatment in a HIV positive patient on antiretroviral therapy. Indian J Dermatol Venereol Leprol. 2018;84(6):758-60.

5. Frampton JE, Basset-Séguin N. Vismodegib: a review in advanced basal cell carcinoma. Drugs. 2018;78(11):1145-56. https://doi.org/10.1007/ s40265-018-0948-9.

6. Matthews BA, Rhee JS, Neuburg M, Burzynski ML, Nattinger AB. Development of the facial skin care index: a health-related outcomes index for skin cancer patients. Dermatol Surg. 2006;32(7):924-34.

7. Finlay AY, Khan GK. Dermatology Life Quality Index (DLQI) - a simple practical measure for routine clinical use. Clin Exp Dermatol. 1994;19(3):210-6.

8. Basset-Séguin N, Hauschild A, Kunstfeld R, et al. Vismodegib in patients with advanced basal cell carcinoma: primary analysis of STEVIE, an international, open-label trial. Eur J Cancer. 2017;86:334-48.

9. Scalvenzi M, Villani A, Costa C, Cappello M. Efficacy and safety of vismodegib in patients with basal cell carcinoma: an Italian center experience. Dermatol Ther. 2019;24:e12971. https://doi.org/10. 1111/dth.12971.

10. Girardi D, Barrichello A, Fernandes G, Pereira A. Targeting the Hedgehog pathway in cancer: current evidence and future perspectives. Cells. 2019;8(2):E153. 
11. Villani A, Fabbrocini G, Cappello M, Costa C, Scalvenzi M. Real-life effectiveness of vismodegib in patients with metastatic and advanced basal cell carcinoma: characterization of adverse events and assessment of health-related quality of life using the Dermatology Life Quality Index (DLQI) test. Dermatol Ther. 2019. https://doi.org/10.1007/s13555019-0303-4.

12. Woltsche N, Pichler N, Wolf I, Di Meo N, Zalaudek I. Managing adverse effects by dose reduction during routine treatment of locally advanced basal cell carcinoma with the Hedgehog inhibitor vismodegib: a single centre experience. J Eur Acad Dermatol Venereol. 2019;33(4):e144-5.

13. Scalvenzi M, Costa C, Cappello M, Villani A. Reply to Woltsche $\mathrm{N}$ et al. Managing adverse effects by dose reduction during routine treatment of locally advanced basal cell carcinoma with the Hedgehog inhibitor vismodegib: a single center experience. J Eur Acad Dermatol Venereol. 2019;33(4):e145-7.

14. Lewis V, Finlay AY. 10 years experience of the Dermatology Life Quality Index (DLQI). J Investig Dermatol. 2004;9(2):169-80.
15. Blackford S, Roberts D, Salek MS, Finlay A. Basal cell carcinomas cause little handicap. Qual Life Res. 1996;5(2):191-4.

16. Rhee JS, Matthews BA, Neuburg M, Smith TL, Burzynski M, Nattinger AB. Skin cancer and quality of life: assessment with the Dermatology Life Quality Index. Dermatol Surg. 2004;30(4 Pt 1):525-9.

17. Skiveren J, Mikkelsen MR, Daugbjerg H, Wulf HC. Skin reactions and quality of life after $\mathrm{X}$-ray therapy of basal cell carcinoma. J Skin Cancer. 2012;2012:825095.

18. Gualdi G, Moro R, Regina V, Caravello S, Monari P, Calzavara-Pinton PG. PRISModegib: the use of the PRISM test to assess the health-related quality of life of patients with locally advanced basal cell carcinoma undergoing Hedgehog pathway inhibitor therapy. Br J Dermatol. 2019. https://doi.org/10. 1111/bjd.17754. 